\title{
A phylogenetic test of the parasite-host associations between Maculinea butterflies (Lepidoptera: Lycaenidae) and Myrmica ants (Hymenoptera: Formicidae)
}

\author{
GUNTHER JANSEN*, KARI VEPSÄLÄINEN and RIITTA SAVOLAINEN \\ Department of Biosciences, P.O. Box 65, 00014 University of Helsinki, Finland; e-mails: Kari.Vepsalainen@helsinki.fi; \\ Riitta.Savolainen@helsinki.fi
}

Key words. Coevolution, host switching, Large blues, local adaptation, Maculinea, Myrmica, Phengaris

\begin{abstract}
The parasitic caterpillars of Maculinea (Lepidoptera: Lycaenidae) need to be adopted and nursed by ants of the genus Myrmica (Hymenoptera: Formicidae). Each Maculinea species is locally associated with one or a few main and often several secondary host species. To determine whether the parasite-host associations bear marks of cophylogenetic constraints, we reconstructed phylogenies of Maculinea and Myrmica using DNA sequence data. We searched for evidence of cospeciation with a treeindependent (ParaFit) and tree-based (TreeFitter) method. This did not reveal any indication of phylogenetic host tracking in $M a c u$ linea. This agrees with earlier insights, which emphasise that as most of the potential host ant populations are never infested by Maculinea, the selective pressure of the butterflies on Myrmica is likely to be slight. Each Maculinea species also specialises on one or a few host plant species before adoption by ants. We suggest that Maculinea species have a substantial potential to accommodate evolutionarily to geographically changing ranges of potential Myrmica hosts, available at the oviposition sites of the butterflies. We use recently published evidence on geographically varying host ant species to discuss a suite of plausible scenarios of adaptive shifts to new Myrmica host species.
\end{abstract}

\section{INTRODUCTION}

Coevolution may be strictly defined as an evolutionary change in a trait of the individuals in one population in response to a trait of the individuals in a second population, followed by an evolutionary response by the individuals in the second population to the change in the individuals in the first population (Janzen, 1980; see also Thompson, 2005). For intimately associated parasites and hosts, where hosts have become allopatrically isolated, and parasites are unable to disperse to or survive on hosts phylogenetically distant to their natural host, coevolution may lead to cospeciation (Reed \& Hafner, 1997). This is a process during which speciation in one group is paralleled by speciation in the other (Hafner \& Nadler, 1988; Page, 1994; Hafner \& Page, 1995; Page \& Charleston, 1998). There is strong evidence for cospeciation if the phylogenetic trees of the two interacting groups show a pattern of shared evolutionary history (Futuyma \& Slatkin, 1983).

Cospeciation has been demonstrated in many systems, e.g., between chewing lice and pocket gophers (Hafner \& Nadler, 1988; Hafner \& Page, 1995), nematodes and primates (Hugot, 1999), Buchnera bacteria and Uroleucon aphids (Clark et al., 2000) and lice and birds (Page et al., 2004; Hughes et al., 2007). Other studies report a partial or no fit between the parasite and host phylogenies in more complex situations, involving parasites infecting multiple hosts. This is the case for Monogenea and fish (Desdevises et al., 2002), lice and passerine birds (Johnson et al., 2002), chewing lice and toucans (Weckstein, 2004), and chewing lice and penguins (Banks et al., 2006).

Butterflies of the genus Maculinea (Lycaenidae) now formally synonymised with Phengaris (Fric et al., 2007, but see Balletto et al., 2010) — show a remarkable parasitic association with their ant hosts. Caterpillars spend most of their life inside a Myrmica colony (Thomas et al., 1989; Elmes et al., 1991a). The caterpillars mimic host brood and are either actively fed by ants (cuckoo species, Maculinea alcon, M. rebeli; Elmes et al., $1991 \mathrm{a}, \mathrm{b}$ ) or prey on the ant brood (predatory species, $M$. arion, M. arionides, $M$. nausithous, M. teleius; Thomas \& Wardlaw, 1992). After living inside a nest for up to two years (Schönrogge et al., 2000; Witek et al., 2006) the adult butterfly emerges inside the nest and escapes before being detected.

To survive in a host colony, Maculinea need to avoid being attacked by the host ant workers. The caterpillars possess a dorsal nectary organ, which produces secretions that are nutritious for ants and probably appease aggressive ants (Pierce et al., 2002; Wardlaw et al., 2000). To avoid being detected as aliens, caterpillars further engage in chemical mimicry or camouflage (Akino et al., 1999). Maculinea rebeli, for example, biosynthesise a cuticular hydrocarbon profile (CHC) similar to its main host, Myr-

\footnotetext{
* Present address: Zoological Institute, Christian-Albrechts University of Kiel, Am Botanischen Garten 1-9, 24118 Kiel, Germany; e-mail: gjansen@zoologie.uni-kiel.de
} 
mica schencki (Akino et al., 1999), which ensures that the host workers react to caterpillars as if they were their own brood.

Because avoidance of detection requires highly specific chemical signals, most Maculinea are expected to associate with one host species (Thomas et al., 1989; Elmes et al., 2002). Nevertheless, M. alcon is found with three different host species in different parts of Western Europe (Elmes et al., 1994; Als et al., 2002). Indeed, recent studies have shown that each Maculinea species may use several hosts (Als et al., 2004 and references therein). Inside a non-optimal host colony, however, the $\mathrm{CHC}$ profile of $M$. rebeli caterpillars differs from that of the host workers (Schönrogge et al., 2004). Although aliens are tolerated in ant colonies when food is plentiful they are killed when conditions become stressful (Elmes \& Wardlaw, 1983; Elmes et al., 2004). Therefore, when predation by the parasite caterpillar stresses the host colony, host workers may eliminate any aliens, including the caterpillar. Consequently, few of the Maculinea adopted by nonoptimal Myrmica hosts survive (Thomas et al., 1989; Als et al., 2001).

Nash et al. (2008) suggest that local populations of Maculinea alcon and Myrmica rubra undergo a coevolutionary arms race with reciprocal $\mathrm{CHC}$ profile adaptation. If so, did Maculinea speciate in parallel with Myrmica diversification? This study aims to investigate whether the interaction of Maculinea with its Myrmica hosts has influenced its phylogeny. Here, we use DNA sequence data to reconstruct phylogenies of the Maculinea parasites and their Myrmica hosts. We then test congruence between these phylogenetic trees using tree- and distancebased methods that search for significant patterns of codiversification.

\section{MATERIALS AND METHODS}

Sequences of Cytochrome Oxidase I, tRNA-Leu and Cytochrome Oxidase II (COI, trnL, COII) and Elongation Factor $1 \alpha$ $(\mathrm{EF}-1 \alpha)$ were downloaded from GenBank for 32 Maculinea specimens (including two species of Phengaris, the genus to which all Maculinea formally belong; Fric et al., 2007) and outgroups Pseudophilotes vicrama, Pseudophilotes baton and Pseudophilotes bavius (data from Als et al., 2004). For Myrmica, we used Cytochrome Oxidase subunit I (COI), Cytochrome b (Cytb), ribosomal 28S extension region 2 (28S), Arginine Kinase (ArgK) exons 1 and 2, the F1 copy of Elongation Factor 1 alpha (EF-1 $\alpha$ ), and Long Wavelength Rhodopsine (LwRh) for a subset of species from our phylogenetic study of Myrmica (Jansen et al., 2010). Most Myrmica species recorded as host for Maculinea (Als et al., 2004 and references therein; Sielezniew \& Stankiewicz, 2004, 2008) were included, except Myrmica gallienii, M. salina (Tartally, 2005) and M. lonae (Tartally et al., 2008), for which samples were unavailable. The outgroups were Manica rubida and Manica invidia. A list of taxa, with collection information and GenBank accession numbers is provided as supplementary material.

The sequences of Maculinea and Myrmica were aligned using Mafft 6.06b (Katoh et al., 2005). The respective alignments were 3173 and 3886 base pairs. The best-fitting models for the alignments of Maculinea and Myrmica were determined using the Akaike information criterion in Modeltest 3.7 (Posada \& Crandall, 1998). Each alignment was analysed in MrBayes
3.1.2. (Ronquist \& Huelsenbeck, 2003). The data were partitioned to genes and the appropriate substitution model (as chosen by AIC) was applied to each partition. For Maculinea two million generations were run, for Myrmica ten million, sampling every $1000^{\text {th }}$ generation. 100,000 and 2 million generations were discarded as burn in, for Maculinea and Myrmica, respectively. A $50 \%$ majority rule consensus tree was calculated from 3,802 and 16,002 trees, respectively. The Maculinea tree was then simplified to contain one terminal for each species.

Currently available cophylogenetic methodologies either directly compare a priori defined host and parasite phylogenies (Page, 1994; Ronquist, 1995; Charleston, 1998; Brooks et al., 2001) or incorporate phylogenetic uncertainty into statistical tests (Huelsenbeck, 1997, 2000; Johnson et al., 2001; Legendre et al., 2002). To test whether two phylogenies are congruent Light \& Hafner (2008) propose a research protocol involving three steps, which was adopted in this study.

To evaluate the possible congruence of the Maculinea and Myrmica phylogenies, the following were considered: (a) all records of parasite-host associations; (b) one host per parasite (i.e., the host traditionally considered most important in Europe, see Table 1) and (c) strategies similar to (a) and (b), but treating M. alcon and M. rebeli as one species (see Fig. 1 for a graphical representation of the associations). The associations were obtained from Als et al. (2004) and references therein and updated with the references cited in Table 1. Because there is geographical host differentiation in M. alcon (Elmes et al., 1998), a single main host could not be assigned; therefore the one-host-per-parasite-analyses were repeated (as in b), each time taking only one of the recorded hosts of $M$. alcon into account.

The data were first analysed using ParaFit (Legendre et al., 2002). This statistical method does not depend on a priori defined phylogenies and is well suited to deal with multiple-host parasites. It uses genetic or patristic (summed branch lengths along a phylogenetic tree) distances to test significance of a global coevolutionary structure and of each parasite-host association. The method tests the null hypothesis that each parasite is associated with its host at random. If a parasite underwent a prolonged period of strict association with its host, there would be significant structure in the parasite tree mirroring that of the host. If one or both trees are unreliable, the program uses genetic distances instead of patristic distances. ParaFit takes as input a parasite-host association matrix (A), a matrix of principal coordinates calculated from pairwise genetic or patristic distances of the parasites (B) and a transposed matrix of principal coordinates for the host $(\mathrm{C})$. The program compares a global trace statistic (ParaFitGlobal, Legendre et al., 2002) calculated from matrix $\mathrm{D}\left(\mathrm{D}=\mathrm{CA}^{\prime} \mathrm{B}\right)$ with the trace values obtained after a random permutation of the A matrix (keeping the same number of associations per parasite). The program tests individual associations in a comparable way.

To calculate pair wise distances in PAUP* (Swofford, 1998) the GTR $+\mathrm{I}$ and GTR $+\mathrm{G}+\mathrm{I}$ models were used for the Maculinea and Myrmica COI alignments, respectively. Patristic distances were also calculated from the parasite and host trees in PAUP*. These matrices were then inserted into DISTPCOA (Legendre \& Anderson, 1998), which yielded principal coordinates for the pairwise genetic and patristic distance matrices of the parasites and hosts. Finally, the significance of parasite-host associations was assessed with 9,999 permutations in ParaFit.

Then the data were analysed using a tree-based method implemented in TreeFitter (Ronquist, 1995). This tests the congruence between two phylogenetic trees by minimising a cost matrix. The user may specify costs associated with four evolutionary events (Ronquist, 1995; Page \& Charleston, 1998): (1) 
TABLE 1. Species of Myrmica recorded as hosts of the European Maculinea species; main host species are in bold. Myrmica species are ordered in an approximate sequence from the most xerotherm to oligotherm species. Country codes: $\mathrm{A}=\mathrm{Austria}, \mathrm{CH}=$ Switzerland, $\mathrm{CZ}=$ Czech, DK $=$ Denmark, $\mathrm{E}=$ Spain, $\mathrm{F}=$ France, $\mathrm{G}=$ Germany, $\mathrm{H}=$ Hungary, LT $=$ Lithuania, $\mathrm{NL}=\mathrm{The}$ Netherlands, $\mathrm{PL}=$ Poland, $\mathrm{RO}=$ Romania, $\mathrm{S}=$ Sweden, $\mathrm{SK}=$ Slovakia, $\mathrm{UA}=$ Ukraine, $\mathrm{UK}=$ United Kingdom. References: ${ }^{1}$ Elmes et al. (1998); ${ }^{2}$ Sielezniew \& Stankiewicz (2002); ${ }^{3}$ Stankiewicz \& Sielezniew (2002); ${ }^{4}$ Höttinger et al. (2003); ${ }^{5}$ Sielezniew et al. (2003); ${ }^{6}$ Steiner et al. (2003) and references therein; ${ }^{7}$ Sielezniew \& Stankiewicz (2004); ${ }^{8}$ Stankiewicz et al. (2005a); ${ }^{9}$ Stankiewicz et al. (2005b); ${ }^{10}$ Tartally (2005); ${ }^{11}$ Tartally \& Varga (2005); ${ }^{12}$ Vályi-Nagy \& Czösz (2007); ${ }^{13}$ Sielezniew \& Stankiewicz (2008); ${ }^{14}$ Tartally \& Varga (2008); ${ }^{15}$ Tartally et al. (2008a); ${ }^{16}$ Tartally et al. (2008b); ${ }^{17}$ Witek et al. (2008); ${ }^{18}$ Wynthoff et al. (2008); ${ }^{19} \mathrm{Nash}$ et al. (2008); ${ }^{20}$ Munguira \& Martin (1999).

\begin{tabular}{|c|c|c|}
\hline Maculinea & Myrmica & Host evaluation, comments, references \\
\hline \multirow[t]{6}{*}{ arion } & hellenica & eastern PL, at this site, sabuleti was not used and the nest density of Myrmica was very low ${ }^{13}$ \\
\hline & rugulosa & eastern PL, at this site, sabuleti was not used and the nest density of Myrmica was very low ${ }^{13}$ \\
\hline & schencki & eastern PL, at this site, sabuleti was not used and the nest density of Myrmica was very low ${ }^{13}$ \\
\hline & sabuleti $^{* *}$ & main host $\mathrm{F}, \mathrm{UK}, \mathrm{S}^{1}$ \\
\hline & scabrinodis & minor host $\mathrm{F}, \mathrm{UK}, \mathrm{S}^{1}$ \\
\hline & lobicornis & a single pupa found ${ }^{4}$ \\
\hline \multirow[t]{8}{*}{ rebeli } & specioides & secondary host $\mathrm{A}^{6}$; occasionally $\mathrm{H}, \mathrm{RO}^{14}$ \\
\hline & rugulosa & one nest ( + in the only sabuleti nest found $)^{8}$ \\
\hline & schencki $^{* *}$ & $\begin{array}{l}\text { main host } \mathrm{F}, \mathrm{E}^{1} \text {; exclusive host } \mathrm{LT}^{9} \text {; one of two main hosts } \mathrm{H}^{12} \\
\text { one of the three species mainly used } \mathrm{H}, \mathrm{RO}^{15} \text {; secondary host } \mathrm{PL}^{6}\end{array}$ \\
\hline & sabuleti & $\begin{array}{l}\text { main host } P L, A, G^{6} \text {; one of two main hosts } \mathrm{H}^{12} \text {; one of the three species mainly used } \mathrm{H}, \mathrm{RO}^{15} \text {; rarely } \\
\text { a host } F, \mathrm{E}^{1}\end{array}$ \\
\hline & lonae & occasionally $\mathrm{H}, \mathrm{RO}^{15}$ \\
\hline & scabrinodis & one of the three species mainly used $\mathrm{H}, \mathrm{RO}^{15}$; secondary host $\mathrm{PL}^{6}$; rarely a host $\mathrm{F}, \mathrm{E}^{1}$ \\
\hline & sulcinodis & secondary host $\mathrm{CH}^{6}$ \\
\hline & ruginodis & rarely a host $\mathrm{F}, \mathrm{E}^{1}$ \\
\hline \multirow[t]{5}{*}{ alcon } & salina & main host at the northeast. $\mathrm{H}$, nearby populations use scabrinodis ${ }^{10}$; occasionally a host $\mathrm{H}, \mathrm{RO}^{15}$ \\
\hline & rubra $^{* *}$ & one of the two main hosts $\mathrm{DK}, \mathrm{S}^{19}$, host $\mathrm{S}^{1}$; secondary host $\mathrm{NL}^{1}$ \\
\hline & scabrinodis $^{* *}$ & only host $\mathrm{E}, \mathrm{F}^{1}$; $\mathrm{PL}, \mathrm{UA}, \mathrm{A}^{2,4,17}$; main host $\mathrm{H}, \mathrm{RO}^{12,15}$; main host with vandeli, south. $\mathrm{PL}^{7}$ \\
\hline & vandeli & main host with scabrinodis, southern $\mathrm{PL}^{7}$; occasionally a host $\mathrm{H}, \mathrm{RO}^{15}$ \\
\hline & ruginodis $^{* *}$ & main host $\mathrm{NL}^{1}$; one of the two main hosts $\mathrm{DK}, \mathrm{S}^{19}$ \\
\hline \multirow[t]{9}{*}{ teleius* $^{*}$} & specioides & found once in $\mathrm{H}, \mathrm{RO}^{14}$ \\
\hline & rugulosa & $\mathrm{PL}, \mathrm{CZ}, \mathrm{SK}, \mathrm{UA}$, at most sites not possible to distinguish primary host (5 spp $)^{17}$ \\
\hline & sabuleti & minor host $\mathrm{F}, \mathrm{PL}^{1}$ \\
\hline & salina & locally important at a few sites $\mathrm{H}, \mathrm{RO}^{14}$ \\
\hline & gallienii & $\begin{array}{l}\mathrm{PL}, \mathrm{CZ}, \mathrm{SK}, \mathrm{UA} \text {, at most sites not possible to distinguish primary host }(5 \mathrm{spp})^{17} \text {; } \\
\text { secondary host (same frequency as in scabrinodis) } \mathrm{PL}^{3} \text {; locally important host (few sites) H, RO }{ }^{14}\end{array}$ \\
\hline & rubra & $\begin{array}{l}\text { main host at western sites } \mathrm{H}, \mathrm{RO}^{14} \text {; highest frequency in } \mathrm{PL}^{3} \text {; } \mathrm{PL}, \mathrm{CZ}, \mathrm{SK}, \mathrm{UA} \text {, at most sites not pos- } \\
\text { sible to distinguish primary host }(5 \mathrm{spp})^{17} \text {; minor host } \mathrm{F}, \mathrm{PL}^{1} \text {; minor host, in same nest with nausithous } \\
\text { in western } \mathrm{H}^{11}\end{array}$ \\
\hline & scabrinodis $^{* *}$ & $\begin{array}{l}\text { only host } \mathrm{NL}^{18} \text {; main host } \mathrm{F}, \mathrm{PL}^{1} \text {; main host at eastern sites } \mathrm{H}, \mathrm{RO}^{14} \text {; secondary host } \mathrm{PL}^{3} \text {; } \\
\mathrm{PL}, \mathrm{CZ}, \mathrm{SK}, \mathrm{UA} \text {, at most sites not possible to distinguish primary host }(5 \mathrm{spp})^{17}\end{array}$ \\
\hline & vandeli & minor host $\mathrm{F}, \mathrm{PL}^{1}$; found once in $\mathrm{H}, \mathrm{RO}^{14}$ \\
\hline & ruginodis & $\mathrm{PL}, \mathrm{CZ}, \mathrm{SK}, \mathrm{UA}$, at most sites not possible to distinguish primary host $(5 \mathrm{spp})^{17}$; one nest $\mathrm{PL}^{3}$ \\
\hline \multirow[t]{3}{*}{ nausithous } & rubra $^{* *}$ & only host $\mathrm{F}, \mathrm{E}, \mathrm{PL}, \mathrm{NL}^{1,3,18}$; main host in western $\mathrm{H}^{11}$; main host in PL, UA ${ }^{17}$ \\
\hline & scabrinodis & the only "potential" host in two isolated populations in $\mathrm{RO}^{16}$; two nests, Kraków region $\mathrm{PL}^{17}$; host $\mathrm{E}^{20}$ \\
\hline & ruginodis & two nests, Kraków region $\mathrm{PL}^{17}$ \\
\hline
\end{tabular}

cospeciation (C): parasite speciation parallel to host; (2) duplication (D): parasite speciation independent of host; (3) host switching $(\mathrm{H})$ : parasite adopted secondary host(s); (4) sorting (S): parasite disappeared from host lineage (e.g., through extinction). These costs are optimised in a generalised parsimony framework: the optimal fit has the lowest global cost. TreeFitter is able to explore the optimal cost settings for a specified range; an interval between zero and four was chosen for all cost categories. The Maculinea-Myrmica associations were analysed using (1) a set of cost settings penalising each of the events in turn, (2) the default settings $(\mathrm{C}=0, \mathrm{D}=0, \mathrm{H}=2, \mathrm{~S}=1)$, (3) the maximum codivergence settings $(\mathrm{C}=-1, \mathrm{D}=0, \mathrm{H}=0, \mathrm{~S}=0)$ and (4) a high cost for codivergence and switching to investigate independent parasite evolution $(\mathrm{C}=10, \mathrm{D}=0, \mathrm{H}=10, \mathrm{~S}=1)$. Ten thousand permutations of the parasite tree were used to determine whether the empirical associations were significantly less costly than associations by chance alone.

\section{RESULTS}

For Maculinea a well resolved tree was recovered. Maculinea arion $+M$. arionides and M. teleius + M. nausithous were separate, well-supported sister clades (posterior probability, $\mathrm{PP}=100$; Fig. 1). Maculinea alcon and $M$. rebeli formed a polytomy without any well supported monophyletic groups. Their relationship to other $\mathrm{Macu}$ - 

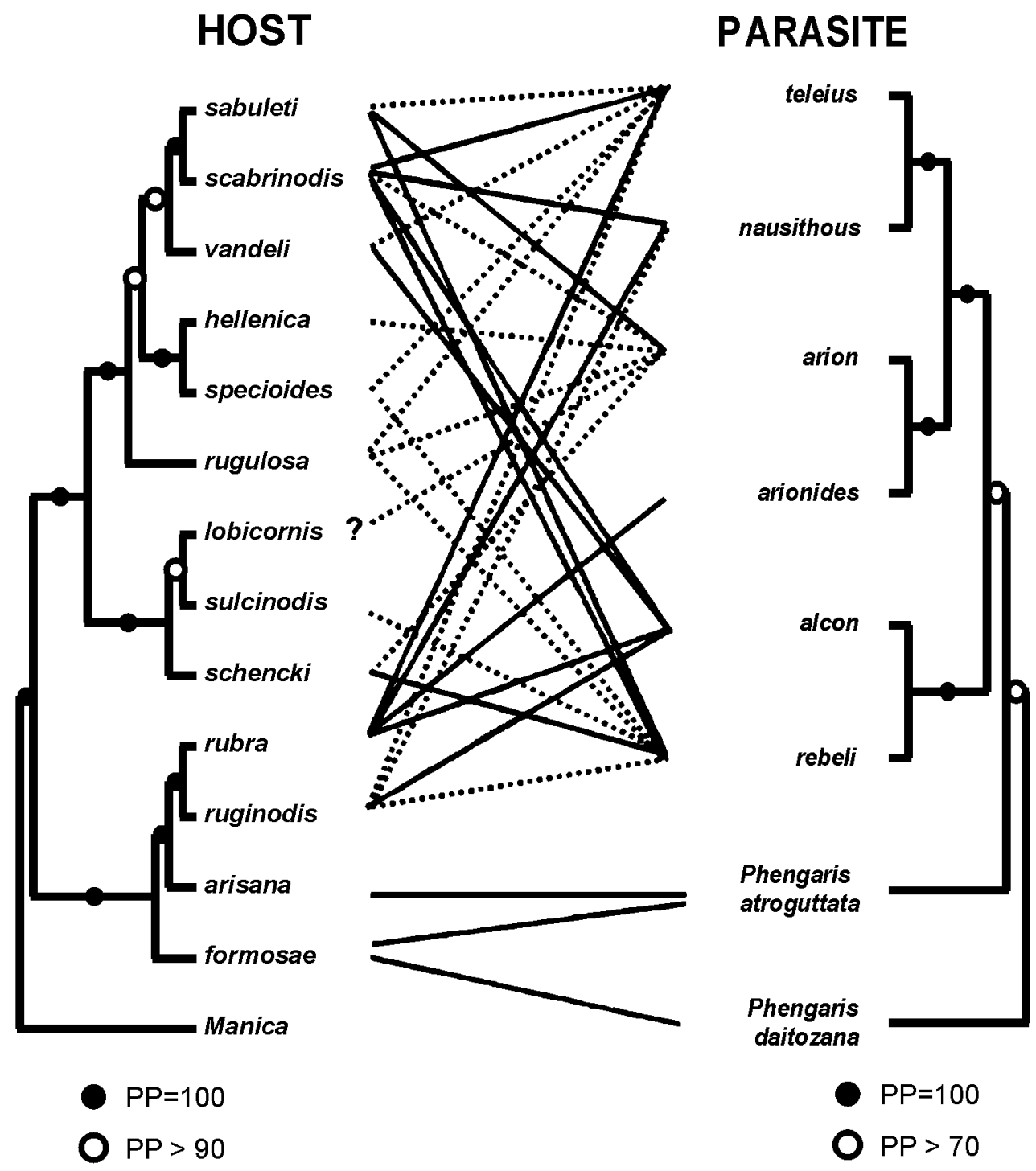

Fig. 1. Graphical representation of the associations of Maculinea parasites and two closely related oriental Phengaris species (right) with their Myrmica hosts (left). The Myrmica and Maculinea phylogenies are the result of Bayesian analyses of data partitioned to genes and an appropriate model chosen by AIC applied to each partition. The analyses were run for two (burn in 10,000) and ten million (burn in 2 million) generations. Full lines indicate main host associations for each species; dashed lines represent secondary or rarely used hosts; for a comprehensive summary of the host species recorded for European Maculinea species, see Table 1. Filled circles indicate $100 \%$ posterior probability; unfilled circles represent a posterior probability higher than $90 \%$ for $M y r-$ mica and higher than $70 \%$ for Maculinea. Note that these phylogenies are based on previous data of one or several specimens per species, the details of which are not presented. Notably, the species in the alcon-rebeli clade were not reciprocally monophyletic.

linea received moderate support $(\mathrm{PP}=76)$. The phylogeny was not investigated further, as our results are identical to those of Als et al. (2004) and the Bayesian tree in Fric et al. (2007). The Myrmica tree was completely resolved, received high support at every node (Fig. 1) and also agrees with the one presented in Jansen et al. (2010). Morphologically known species groups were recovered as monophyletic: scabrinodis (the clade containing M. sabuleti and M. rugulosa), lobicornis ( $M$. lobicornis and M. sulcinodis), and rubra (M. rubra, M. ruginodis and $M$. arisana).

The tree-independent method (ParaFit) returned a non significant ParaFitGlobal statistic and non significant individual associations, except for M. teleius and Myr- mica rubra $(\mathrm{P}=0.018)$. The analysis was repeated, taking into account only the traditional main host for each parasite species, which did not yield a significant global statistic, nor any statistically significant individual association. Changing the main host for M. alcon or treating $M$. alcon and $M$. rebeli as one species did not alter the results. Finally, the use of patristic distances was to no avail. No similarity could be found between the parasite and host phylogenies.

In the tree-based analysis (TreeFitter), the exploration of the cost space (all possible combinations of values between zero and four for each parameter) did not yield a single optimal solution and no solution received a P-value below 0.06 . Therefore, there was no objective criterion to 
select one cost setting over another. When taking into account all recorded parasite-host associations, the global cost of the optimal reconstruction was never significantly lower than costs obtained after 10,000 random rearrangements of the parasite tree. All reconstructions implied a number of switches, unless a very high cost was set for switching. The above analysis was repeated, considering only the traditional main host for each parasite species. Again, the cost estimation failed to produce a significant solution. This did not change when the data were analysed using different hosts for $M$. alcon or when M. alcon and $M$. rebeli were treated as one species. The parasite tree was fitted using the same settings as before, and failed to recover any significant coevolutionary signal in the Maculinea tree. Evidently, the parasite-host associations are random and not shaped by cospeciation.

\section{DISCUSSION}

Clearly, the Maculinea and Myrmica phylogenies were not congruent. Incongruent parasite and host phylogenies, however, do not imply that coevolution did not occur in the evolutionary history of the parasites and their hosts. Literature abounds with examples why coevolution is not detected. For example, cophylogenetic methods may fail to recover a significant pattern because of phylogenetic uncertainty (Johnson et al., 2002) or multiple-host parasites (Banks \& Paterson, 2005).

The Maculinea tree obtained in this study is congruent with that recorded in the literature (Als et al., 2004; Fric et al., 2007) and received good support. The Myrmica phylogeny was derived from several gene fragments and corroborated most morphologically defined species groups (Seifert, 1988; Radchenko 1995; Radchenko \& Elmes, 2001; Jansen et al., 2010). Thus, incorrect host or parasite trees do not explain their mutual incongruence. If each Maculinea species uses Myrmica species belonging to at least the same species-group clade then this would support the co-speciation hypothesis. Visual inspection of the tanglegram (Fig. 1) reveals that this is not the case; even the main host species tend to belong to more than one Myrmica species group. Nevertheless, to accommodate the possibility of phylogenetic uncertainty, a ParaFit with distance data was applied. This method estimates coevolutionary statistics independent of any a priori defined phylogenetic structure (Legendre et al., 2002). Again, no congruence was found.

Maculinea species are obligately dependent on their Myrmica host species, but only a minute proportion of the potential host colonies are infected with this parasite (Elmes et al., 1998). However, until recently the cospeciation hypothesis seemed plausible; still in the early 2000s it was believed that Maculinea species are mainly dependent on a single host species (Thomas et al., 2005). Currently, however, a great diversity of host species is recorded (Table 1), although the significance of many of the host species for the survival of Maculinea populations is poorly documented. As emphasised by Thomas et al. (2005), successful rearing of Maculinea in a nest of Myrmica, or finding caterpillars close to pupation in a field nest, does not prove that that specific host species could maintain the local parasite population. To prove this, more detailed life-history and survival studies are needed.

In spite of these uncertainties, the high diversity of host species reported recently (Table 1) suggests that host ant exploitation by Maculinea is fairly flexible, even locally, indicating a potential for shifting to a new main host. The current pattern is one of geographical variation in the use of the main host species and there is no reason why the potential for host shift should be only historical (as would be the case if cospeciation had occurred).

Notably, even though the presence of the right host species is vital for any Maculinea population, their main limiting resource seems to be their host plant, each species usually using locally or even globally only one or a few closely related food plant species in the period prior to their adoption by the host ant (Munguira \& Martin, 1999). The availability of food plants rather than the presence of ant nests determine the oviposition patterns of Maculinea species (Thomas \& Elmes, 2001). Because the species composition of Myrmica nesting close to the obligate food plant may differ geographically (Thomas et al., 1998), there probably is strong selection for Maculinea to adapt to the regional or local Myrmica species nesting close to the food plants of the caterpillars of the butterfly. This geographical variation in host use may thus be interpreted as a result of coevolutionary dynamics (as defined by Janzen, 1980 and Thompson, 2005) involving locally restricted arms races (Nash et al., 2008). The results presented demonstrate that coevolution and cospeciation are evolutionarily distinct phenomena and the former does not necessarily imply the latter.

The likelihood of a host shift depends on the specific lifestyle of the parasite. There are striking differences between the predatory and cuckoo-feeding Maculinea species in their relations with their host ants, but for different reasons, both predatory and cuckoo-feeding species have evolved a more or less general Myrmica-like CHC profile. The cuckoo-feeding caterpillar is taken by host workers to the brood chamber, where it is fed by nurse ants. In the nest of secondary hosts, in benign situations, the caterpillar keeps a general Myrmica-like profile, probably acquired passively from the host (Schönrogge, 2004). However, after isolation from the host nest the same caterpillars are able to synthesise additional compounds that cannot be acquired from the secondary host, but resemble the $\mathrm{CHC}$ of the main host (Schönrogge et al., 2004). Thus it is likely that these compounds can be produced by the caterpillar, but their production is suppressed in secondary host colonies. However, in foodstressed colonies the caterpillars probably synthesise the main-host-specific CHCs to facilitate begging for food. In this case close mimicry of the main host would prove fatal for the parasite, whereas in stressed nests of the main host the synthesis of the same compounds elevates the status of the caterpillar, probably to a level equivalent to that of the host queen (Thomas et al., 2005).

When predatory Maculinea caterpillars are taken into a host nest, they attach a patch of silk to the roof of an outer 
chamber, from where they make short foraging bouts to the brood chamber to feed on large ant larvae. Unfortunately, there is little information on the changes in the CHC profiles of predatory Maculinea species, but their less intimate association with host ants compared to the cuckoo species may theoretically exert a lower selective pressure to match the $\mathrm{CHC}$ profile of the host.

In summary, the main difference between the two Maculinea strategies seems to be a higher risk of the cuckoo-feeding caterpillars being killed in food-stressed colonies of secondary hosts, potentially leading to higher host specificity of cuckoo species. However, this expectation is not supported by field data, as the predatory $M$. nausithous are the most host-specific Maculinea (Tartally, 2008a). This may be explained by the mitigating effect of an additional adaptation. Recently, Barbero et al. (2009a, b) showed that the caterpillars and pupae of both a cuckoo-feeding and a predatory $\mathrm{Macu}$ linea species mimic the stridulation of the queen of their main host and so achieve a high status within the ant society. Notably, the sounds made by queens of the three Myrmica species studied were indistinguishable. Given the possible universal efficiency of acoustic communication, the close chemical adaptation of cuckoo-feeding Maculinea species could still be a strong selective force in stressed nests of secondary host species effectively working against host shifts.

For predatory Maculinea not specialising chemically to beg food in continuous close contact with the host, selection against host specialisation could still occur because their lifestyle requires a much larger number of host colonies than the cuckoo-feeding species (Thomas et al., 2005). In spite of the differences in the life-styles of predatory and cuckoo-feeding species, host shifts are recorded for species in both groups (Table 1). Below are presented a set of hypothetical adaptive mechanisms that could operate in both groups of Maculinea subject to selection to shift between hosts, e.g., when next to food plants of the caterpillar a secondary host species outnumbers the traditional, locally rare main host. The models are classified on the basis of plausible parasite-host scenarios.

\section{One stable main host and the evolutionary potential for increasing the exploitation of that host}

When colonies of the main host are abundant, then adaptation to that host species is expected to become evolutionarily fixed. This outcome is recorded for cuckoofeeding Maculinea species over large geographical areas along with the connate ability to synthesise a host-species mimicking odour. However, because "a species, like a sponge, soaks up heterozygous (recessive) mutations while remaining from first to last externally (phenotypically) homogeneous" (Chetverikov, 1926), populations maintain genetic potential for adaptive evolution (Schmalhausen, 1949; Lewontin, 1974; Wilkins, 2001). Hence, the expectation is that Maculinea populations with one stable host maintain a high standing genetic variation.

\section{Traditional main host scarce, but secondary host abundant}

When the habitat of a specific host species changes (e.g., when moving from one geographical region to another, or locally over long periods of time), the vital spatial correlation between the locations of the nests of the main host and the caterpillar's host plant may break down, and other potential host species may occupy the space close to the host plants. Then, there will be a strong selective pressure that favours those genetic variants that have $\mathrm{CHC}$ patterns close to those of the new, numerically dominant host species. Even though chemical closeness of the old and new host species is expected to facilitate a host shift, serendipitous adaptation may take place. For example, Hojo and coworkers (Akino, 2008; Hojo et al., 2009) described that Camponotus japonicus (the only host of the lycaenid Niphanda fusca) brings caterpillars to its nest and after adoption, these caterpillars synthesise CHCs that are more similar to those of the male ants than worker ants with which the caterpillars live, which is an unexpected but efficient means of raising the status of the caterpillars within the ant colony.

\section{Main local host species varies in abundance in time}

Sometimes the main host becomes rare because of the effect the parasite has on the survival of its colonies, whereas a secondary host may be temporally unaffected. If the $\mathrm{CHC}$ profiles of two temporally alternating potential host species are relatively similar, genetic variation may allow tracking of the available host species. Such see-sawing between two adaptive peaks seems to fit the shifting host use of Myrmica rubra and M. ruginodis by Maculinea alcon in Denmark, reported by Nash et al. (2008).

\section{No reliable single host, but a combination of two hosts might suffice}

If the combined nest density of two permanent host species is sufficient to maintain the parasite population, but that of one of the species would not, selection may favour an individual-level CHC profile that is a mix of the CHC patterns of the hosts. Such a tactic is close to that described by Schlick-Steiner et al. (2004). In Central Europe the cuckoo-feeding Maculinea rebeli has one main and several secondary host species, and rather than emitting a general Myrmica-like odour the pre-retrieval caterpillars synthesise an aggregate odour containing specific compounds of at least two host species. Because fine-tuned active synthesis of host-specific CHC starts in the cuckoo-feeders only several days after adoption by the host ant, it is unlikely that the fine-tuning could result in the production of $\mathrm{CHC}$ profiles of more than one host species. Such a system would be very costly and after adoption there is no selection for aggregate-odour mimicry. The pre-retrieval mixed synthesis could, however, facilitate the evolution of fine-tuned mimicry of the realised host after adoption, when more than one host species is needed to maintain the population.

Adaptation to the realised host species of a set of more or less equally probable host species is theoretically plau- 
sible, hence future studies should concentrate on finding such situations in natural populations. A prerequisite to individual developmental flexibility of fine-tuned adaptation is an environmental signal that reliably correlates with the realised host species. In Maculinea, such a signal would be the odour (CHC pattern) of the host colony. Then selection could act on the available genetic variation in the parasite, such that a cuckoo-feeding caterpillar's $\mathrm{CHC}$ synthesis is switched to mimicking the $\mathrm{CHC}$ of the realised host.

A flexible norm of reaction, a concept that includes phenotypic plasticity of $\mathrm{CHC}$ profile expression in insects, by which an organism with a specific genotype undergoes adaptive modifications triggered by environmental factors (Schmalhausen, 1949; Levins, 1968), is a wide-spread phenomenon in the animal and plant kingdoms (West-Eberhard, 2003). For example, in the water strider Gerris odontogaster, wing length (short or long wings) and mode of reproduction (direct or post-diapause reproduction) are determined by photoperiod with temperature as a modifying environmental cue (no genetic switch). Notably, developmental plasticity in water striders may vary among individuals, populations and species, depending on how genetic switches and environmental cues interact in determining the physiological and morphological features of the phenotype, and as a result the life-history of a species is also contingent on the geographical location of the population (for a review, see Vepsäläinen, 1978).

Currently little is known about the reaction norms of Maculinea, and as far as we are aware nothing is known about potential switch mechanisms in the context of chemical mimicry, although the fact that host switching may be successful under certain conditions may be deduced from the data provided by Schönrogge et al. (2004). The concept of reaction norms provides intriguing testable hypotheses of chemical host exploitation by these parasites. The great variety of different chemical tactics used by parasites to break in to host domains - see reviews by Lenoir et al. (2001) and Akino (2008) however, indicate a variety of potential case-specific switch mechanisms. Hopefully the studies referred to in Table 1 (e.g., Sielezniew \& Stankiewicz, 2008; Tartally et al., 2008a, b) will encourage a theoretically and empirically broader approach to studies of adaptive shifts and modifications of the chemical mimicry of Maculinea of potential host species.

Thus, in order to study the adaptive pathways in $\mathrm{Macu}$ linea species associated with their host use, locally paired samples of Maculinea and their realised Myrmica host species need to be collected in various geographical regions, where it is known that Maculinea show differences or variation in host use (cf. Nash et al., 2008 for Denmark), i.e., shift the focus to the population level in those regions where strong selection favouring exploitation of a new host is expected or has been realised. Both Maculinea and Myrmica phylogenies should then be reconstructed to determine whether there are cryptic species (in both host and parasite) and whether adaptive evo- lution has occurred in the parasite and the host through host shifts. Furthermore, to shed light on the adaptation of Maculinea caterpillars to the local host species they exploit, the $\mathrm{CHC}$ profiles of local parasite-host pairs should be analysed following the experimental design of Schönrogge et al. (2004), including both the pre-adoption and post-adoption $\mathrm{CHC}$ profiles of the caterpillars.

ACKNOWLEDGEMENTS. This study was funded by the Finnish Cultural Foundation, the Ella and Georg Ehrnrooth foundation (to GJ) and the Finnish Academy of Sciences (to RS). We thank G. Elmes for very helpful discussion and comments on various versions of the manuscript.

\section{REFERENCES}

AkINo T. 2008: Chemical strategies to deal with ants: a review of mimicry, camouflage, propaganda, and phytomimesis by ants (Hymenoptera: Formicidae) and other arthropods. Myrmecol. Nachr. 11: 173-181.

Akino T., Knapp J.J., Thomas J.A. \& Elmes G.W. 1999: Chemical mimicry and host specificity in the butterfly Maculinea rebeli, a social parasite of Myrmica ant colonies. Proc. R. Soc. (B, Biol. Sci.) 266: 1419-1426.

Als T.D., Nash D.R. \& Boomsma J.J. 2001: Adoption of parasitic Maculinea alcon caterpillars (Lepidoptera: Lycaenidae) by three Myrmica ant species. Anim. Behav. 62: 99-106.

Als T.D., Nash D.R. \& Boomsma J.J. 2002: Geographical variation in host-ant specificity of the parasitic butterfly Maculinea alcon in Denmark. Ecol. Entomol. 27: 403-414.

Als T.D., Vila R., Kandul N.P., Nash D.R., Yen S.-H., Hsu Y.-F., Mignault A.A., Boomsma J.J. \& Pierce N.E. 2004: The evolution of alternative parasitic life histories in large blue butterflies. Nature 432: 386-390.

Balletto E., Bonelli S., Settele J., Thomas J.A., Verovnik R. \& Wahlberg N. 2010: Case 3508: Maculinea Van Eecke, 1915 (Lepidoptera: Lycaenidae): proposed precedence over Phengaris Doherty, 1891. Bull. Zool. Nomencl. 67: 129-132.

BANKS J.C. \& PATERSON A.M. 2005: Multi-host parasite species in cophylogenetic studies. Internat. J. Parasitol. 35: 741-746.

Banks J.C., Palma R.L. \& Paterson A.M. 2006: Cophylogenetic relationships between penguins and their chewing lice. J. Evol. Biol. 19: 156-166.

Barbero F., Thomas J.A., Bonelli S., Balletto E. \& SchönROGGE K. 2009a: Queen ants make distinctive sounds that are mimicked by a butterfly social parasite. Science 323: 782-785.

Barbero F, Bonelli S., Thomas J.A., Balletto E. \& SchönROGGE K. 2009b: Acoustic mimicry in a predatory social parasite of ants. J. Exp. Biol. 212: 4084-4090.

Brooks D.R., van Veller M.G.P. \& McLennan D.A. 2001: How to do BPA, really. J. Biogeogr. 28: 345-358.

Charleston M.A. 1998: Jungles: a new solution to the host/parasite phylogeny reconciliation problem. Math. Biosci. 149: 191-223.

Chetverikov S.S. 1926. About some moments of evolutionary process from the point of view of contemporary genetics. $\mathrm{Zh}$. Eksperim. Biol. (A) 2: 3-54 [English translation 1961 in Proc. Am. Philos. Soc. 105: 167-195].

Clark M.A., Moran N.A., Baumann P.U. \& Wernegreen J.J. 2000: Cospeciation between bacterial endosymbionts (Buchnera) and a recent radiation of aphids (Uroleucon) and pitfalls of testing for phylogenetic congruence. Evolution 54: $517-525$. 
Desdevises Y., Morand S., Jousson O. \& Legendre P. 2002: Coevolution between Lamellodiscus (Monogenea: Diplectanidae) and Sparidae (Teleostei): the study of a complex hostparasite system. Evolution 56: 2459-2471.

Elmes G.W. \& WardLAW J.C. 1983: A comparison of the effect of a queen on the development of large hibernated larvae of six species of the genus Myrmica. Insectes Soc. 30: 134-148.

Elmes G.W., WardLaw J.C. \& Thomas J.A. 1991a: Larvae of Maculinea rebeli, a large-blue butterfly, and their Myrmica host ants: wild adoption and behaviour in ant-nests. J. Zool. 223: $447-460$.

Elmes G.W., Wardlaw J.C. \& Thomas J.A. 1991b: Larvae of Maculinea rebeli, a large-blue butterfly, and their Myrmica host ants: patterns of caterpillar growth and survival. J. Zool. 224: 79-92.

Elmes G.W., Thomas J.A., Hammarsted O., Munguira M.L., Martin J., van DER MAde J. 1994: Differences in host-ant specificity between Spanish, Dutch and Swedish populations of the endangered butterfly, Maculinea alcon (Denis et Schiff.) (Lepidoptera). Memor. Zool. 48: 55-68.

Elmes G.W., Thomas J.A., Wardlaw J.C., Hochberg M.E., Clarke R.T., Simcox D.J. 1998: The ecology of Myrmica ants in relation to the conservation of Maculinea butterflies. $J$. Insect Conserv. 2: 67-78.

Elmes G.W., Akino T., Thomas J.A., Clarke R.T. \& Knapp J.J. 2002: Interspecific differences in cuticular hydrocarbon profiles of Myrmica ants are sufficiently consistent to explain host specificity by Maculinea (large blue) butterflies. Oecologia 130: 525-535.

Elmes G.W., Wardlaw J.C., Schönrogge K., Thomas J.A. \& Clarke R.T. 2004: Food stress causes differential survival of socially parasitic caterpillars of Maculinea rebeli integrated in colonies of host and non-host Myrmica ant species. Entomol. Exp. Appl. 110: 53-63.

Fric Z., Wahlberg N., Pech P. \& ZrzavÝ J. 2007: Phylogeny and classification of the Maculinea-Phengaris clade (Lepidoptera: Lycaenidae): total evidence and phylogenetic species concept. Syst. Entomol. 32: 558-567.

Futuyma D.J. \& Slatkin M. 1983: Introduction to coevolution. In Futuyma D.J. \& Slatkin M. (eds): Coevolution. Sinauer Associates, Sunderland, MA, pp. 1-13.

HafNer M.S. \& NadLer S. 1988: Phylogenetic trees support the coevolution of parasites and their hosts. Nature 332: 258-259.

HafNer M.S. \& Page R.D.M. 1995: Molecular phylogenies and host-parasite cospeciation: Gophers and lice as a model system. Phil. Trans. R. Soc. (B, Biol. Sci.) 332: 31-39.

Hojo M.K., Wada-Katsumata A., Akino T., Yamaguchi S., OZAKI M. \& YAMAOKA R. 2009: Chemical disguise as particular caste of host ants in the ant inquiline parasite Niphanda fusca (Lepidoptera: Lycaenidae). Proc. R. Soc. (B, Biol. Sci.) 276: 551-558.

Höttinger H., Schlick-Steiner B.C. \& Steiner F.M. 2003: The Alcon blue Maculinea alcon (Lepidoptera: Lycaenidae) in eastern Austria: status and conservation measures. Ekologia (Bratislava) 22: 107-118.

Huelsenbeck J.P., Rannala B. \& Yang Z. 1997: Statistical tests of host-parasite cospeciation. Evolution 51: 410-419.

Huelsenbeck J.P., Rannala B. \& Larget B. 2000: A Bayesian framework for the analysis of cospeciation. Evolution 54: 352-364.

Hughes J., Kennedy M., Johnson K.P., Palma R.L. \& Page R.D.M. 2007: Multiple cophylogenetic analyses reveal frequent cospeciation between Pelecaniform birds and Pectinopygus lice. Syst. Biol. 56: 232-251.

Hugot J.P. 1999: Primates and their pinworm parasites: the Cameron hypothesis revisited. Syst. Biol. 48: 523-546.
Jansen G., Savolainen R. \& Vepsäläinen K. 2010: Phylogeny, divergence-time estimation, biogeography and social parasitehost relationships of the Holarctic ant genus Myrmica (Hymenoptera: Formicidae). Mol. Phylogenet. Evol. 56: 294-304.

JANZEN D.H. 1980: When is it coevolution? Evolution 34: 611-612.

Johnson K.P., Drown D.M. \& Clayton D.H. 2001: A data based method of cophylogenetic analysis. Zool. Scripta 30: $79-87$.

Johnson K.P., Adams R.J. \& Clayton D.H. 2002: The phylogeny of the louse genus Brueelia does not reflect host phylogeny. Biol. J. Linn. Soc. 77: 233-247.

Катон K., Kuma K., Тон H. \& Miyata T. 2005: MAFFT version 5: improvement in accuracy of multiple sequence alignment. Nucl. Acids Res. 33: 511-518.

Legendre P. \& Anderson M.J. 1998: Program DISTPCOA. Département des sciences biologiques, Université de Montréal.

Legendre P., Desdevises Y. \& Bazin E. 2002: A new statistical method to assess host-parasite coevolution. Syst. Biol. 51: 217-234.

Lenoir A., D'Ettorre P., Errard C. \& Hefetz A. 2001: Chemical ecology and social parasitism in ants. Annu. Rev. Entomol. 46: 573-599.

Levins R. 1968: Evolution in Changing Environments. Some Theoretical Explorations. Princeton University Press, Princeton, NJ, $132 \mathrm{pp}$.

Lewontin R.C. 1974: The Genetic Basis of Evolutionary Change. Columbia University Press, New York, NY, 346 pp.

Light J. \& HafNer M.S. 2008: Codivergence in Heteromyid rodents (Rodentia: Heteromyidae) and their sucking lice of the genus Fahrenholzia (Phthiraptera: Anoplura). Syst. Biol. 57: 449-465.

Munguira M.L. \& Martin J. 1999: Action Plan for the Maculinea Butterflies in Europe. Nature and Environment, No. 97. Council of Europe Publishing, Strasbourg, 64 pp.

Nash D.R., Als T.D., Maile R., Jones G.R. \& Boomsma J.J. 2008: A mosaic of chemical coevolution in a Large Blue butterfly. Science 319: 88-90.

PAGE R.D.M. 1994: Parallel phylogenies: reconstructing the history of host-parasite assemblages. Cladistics 10: 155-173.

Page R.D.M. \& Charleston M.A. 1998: Trees within trees: phylogeny and historical associations. Trends Ecol. Evol. 13: 356-359.

Page R.D.M., Cruickshank R., Dickens M., Furness R.W., KenNedy M., Palma R.L. \& Smith V.S. 2004: Phylogeny of "Philoceanus complex" seabird lice (Phthiraptera: Ischnocera) inferred from mitochondrial DNA sequences. Mol. Phylogenet. Evol. 30: 633-652.

Pierce N.E., Braby M.F., Heath A., Lohman D.J., Mathew J., Rand D.B. \& Travassos M.A. 2002: The ecology and evolution of ant association in the Lycaenidae (Lepidoptera). Ann. Rev. Entomol. 47: 733-771.

Posada D. \& Crandall K.A. 1998: Modeltest: Testing the model of DNA substitution. Bioinformatics 14: 817-818.

RADChENKo A.G. 1995: Taxonomic structure of the ant genus Myrmica (Hymenoptera, Formicidae) of Eurasia. Communication I. Entomol. Rev. 74: 91-106.

RAdChENKo A.G. \& Elmes G.W. 2001: A taxonomic revision of the ant genus Myrmica Latreille (Hymenoptera, Formicidae) from the Himalaya. Entomol. Brasil. 23: 237-276.

ReEd D.L. \& HafNer M.S. 1997: Host specificity of chewing lice on pocket gophers: a potential mechanism for cospeciation. J. Mammal. 78: 655-660. 
RonQuist F. 1995: Reconstructing the history of host-parasite associations using generalised parsimony. Cladistics 11: 73-89.

RonQuist F. \& HuelsenbeCK J.P. 2003: MrBayes 3: Bayesian phylogenetic inference under mixed models. Bioinformatics 19: $1572-1574$.

Schlick-Steiner B.C., Steiner F.M., Höttinger H., Nikiforov A., Mistrik R., Schafellner C., Baier P. \& Christian E. 2004: A butterfly's chemical key to various ant forts: intersection-odour or aggregate-odour multi-host mimicry? Naturwissenschaften 91: 209-214.

Schmalhausen I.I. 1949: Factors of Evolution. The Theory of Stabilizing Selection. The University of Chicago Press, Chicago, IL, 327 pp.

Schönrogge K., Wardlaw J.C., Thomas J.A. \& Elmes G.W. 2000: Polymorphic growth rates in myrmecophilous insects. Proc. R. Soc. (B, Biol. Sci.) 267: 771-777.

Schönrogge K., Wardlaw J.C., Peters A.J., Everett S., Thomas J.A. \& Elmes G.W. 2004: Changes in chemical signature and host specifity from larval retrieval to full social integration in the myrmecophilous butterfly Maculinea rebeli. $J$. Chem. Ecol. 30: 91-107.

SEIFERT B. 1988: A taxonomic revision of the Myrmica species of Europe, Asia Minor, and Caucasia (Hymenoptera, Formicidae). Abh. Ber. Naturkdemus. Görlitz 62: 1-75.

Sielezniew M. \& Stankiewicz A.M. 2002: First data on hostspecifity of parasitic Maculinea arion (Den. \& Schiff.) (Lepidoptera: Lycaenidae) in Poland and eastern Europe. Fragm. Faun. 45: 123-130.

Sielezniew M. \& Stankiewicz A.M. 2004: Simultaneous exploitation of Myrmica vandeli and M. scabrinodis (Hymenoptera: Formicidae) colonies by the endangered myrmecophilous butterfly Maculinea alcon (Lepidoptera: Lycaenidae). Eur. J. Entomol. 101: 693-696.

Sielezniew M. \& Stankiewicz A.M. 2008: Myrmica sabuleti (Hymenoptera: Formicidae) not necessary for the survival of the population of Phengaris (Maculinea) arion (Lepidoptera: Lycaenidae) in eastern Poland: Lower host specificity or evidence for geographical variation of an endangered social parasite? Eur. J. Entomol. 105: 637-641.

Sielezniew M., Stankiewicz A. \& Bystrowski C. 2003: First observation of one Maculinea arion pupa in a Myrmica lobicornis nest in Poland. Nota Lepidopterol. 25: 249-250.

Stankiewicz A. \& Sielezniew M. 2002: Host specifity of Maculinea teleius Bgstr. and M. nausithous Bgstr. (Lepidoptera: Lycaenidae) the new insight. Ann. Zool. 52: 403-408.

Stankiewicz A., Sielezniew M. \& Barański M. 2005a: The first record of Myrmica rugulosa Nylander, 1849 (Hymenoptera: Formicidae) as a host-ant of Maculinea rebeli Hirschke, 1904 (Lepidoptera: Lycaenidae). Pol. Pis. Entomol. 74: 99-103.

Stankiewicz A., Sielezniew M. \& Švitra G. 2005b: Myrmica schencki (Hymenoptera: Formicidae) rears Maculinea rebeli (Lepidoptera: Lycaenidae) in Lithuania: new evidence for geographical variation of host-ant specificity of an endangered species. Myrmecol. Nachr. 7: 51-54.

Steiner F.M., Sielezniew M., Schlick-Steiner B.C., Höttinger H., Stankiewicz A. \& Górnicki A. 2003: Host specificity revisited: New data on Myrmica host ants of the lycaenid butterfly Maculinea rebeli. J. Ins. Cons. 7: 1-6.

Swofford D.L. 1998: PAUP*. Phylogenetic Analysis Using Parsimony (* and other methods). Version 4. Sinauer Associates, Sunderland, MA.

TARTAlly A. 2005: Myrmica salina (Hymenoptera: Formicidae) as a host of Maculinea alcon (Lepidoptera: Lycaenidae). Sociobiology 46: 39-43.
Tartally A. \& Varga Z. 2005: Myrmica rubra (Hymenoptera: Formicidae): the first data on host-ant specificity of Maculinea nausithous (Lepidoptera: Lycaenidae) in Hungary. Myrmecol. Nachr. 7: 55-59.

TARTAlly A. \& VARga Z. 2008: Host ant use of Maculinea teleius in the Carpathian Basin (Lepidoptera: Lycaenidae). Acta Zool. Acad. Sci. Hungar. 54: 257-268.

Tartally A., Nash D.R., Lengyel S. \& Varga Z. 2008a: Patterns of host ant use by sympatric populations of Maculinea alcon and M. 'rebeli' in the Carpathian Basin. Insectes Soc. 55: 370-381.

Tartally A., Rakosy L., Vizauer T.C., Goia M. \& Varga Z. 2008b: Maculinea nausithous exploits Myrmica scabrinodis in Transylvania: unusual host ant species of a myrmecophilous butterfly in an isolated region (Lepidoptera: Lycaenidae; Hymenoptera: Formicidae). Sociobiology 51: 373-380.

Thomas J.A. \& Elmes G.W. 2001: Food-plant niche selection rather than the presence of ant nests explains oviposition patterns in the myrmecophilous butterfly genus Maculinea. Proc. R. Soc. (B, Biol. Sci.) 268: 471-477.

Thomas J.A. \& WardLaW J.C. 1992: The capacity of a Myrmica ant to support a predacious species of Maculinea butterfly. Oecologia 91: 101-109.

Thomas J.A., Elmes G.W., Wardlaw J.C. \& Woyciechowski M. 1989: Host specificity among Maculinea butterflies in Myrmica ant nests. Oecologia 79: 452-457.

Thomas J.A., Simcox D.J., Wardlaw J.C., Elmes G.W., Hochberg M.E. \& Clarke R.T. 1998: Population dynamics in the genus Maculinea (Lepidoptera: Lycaenidae). In Dempster J.P. \& McLean I.F.G. (eds): Insect Populations. Chapman \& Hall, London, pp. 261-290.

Thomas J.A., Schönrogge K. \& Elmes G.W. 2005: Specializations and host associations of social parasites of ants. In Fellowes M., Holloway G. \& Rolff J. (eds): Insect Evolutionary Ecology. Royal Entomological Society, London, pp. 475-514.

Thompson J.N. 2005: The Geographic Mosaic of Coevolution. University of Chicago Press, Chicago, IL, $400 \mathrm{pp}$.

VÁlyi Nagy M. \& Czösz S. 2007: Host ant specificity of the Large Blue butterfly, Maculinea alcon (Denis \& Schiffermüller, 1775), in the Carpathian Basin (Hymenoptera; Formicidae; Lepidoptera: Lycaenidae). Myrmecol. News 10: 124.

VEPSÄLÄINEN K. 1978: Wing dimorphism and diapause in Gerris: determination and adaptive significance. In Dingle H. (ed.): The Evolution of Insect Migration and Diapause. Springer, Berlin, pp. 218-253.

Wardlaw J.C., Thomas J.A. \& Elmes G.W. 2000: Do Maculinea rebeli caterpillars provide vestigial mutualistic benefits to ants when living as social parasites inside Myrmica ant nests? Entomol. Exp. Appl. 95: 97-103.

WECKSTEIN J.D. 2004: Biogeography explains cophylogenetic patterns in toucan chewing lice. Syst. Biol. 53: 154-164.

West-Eberhard M.J. 2003: Developmental Plasticity and Evolution. Oxford University Press, New York, NY, 794 pp.

WILKIns A.S. 2001: The Evolution of Developmental Pathways. Sinauer Associates, Massachusetts, 603 pp.

Witek M., Śliwińska E.B., Skórka P., Nowicki P., Settele J. \& WOYCIECHOWSKI M. 2006: Polymorphic growth in larvae of Maculinea butterflies, as an example of biennialism in myrmecophilous insects. Oecologia 148: 729-733.

Witek M., Śliwińska E.B., Skórka P., Nowicki P., Wantuch M., Vrabec V., Settele J. \& Woyciechowski M. 2008: Host ant specifity of large blue butterflies Phengaris (Maculinea) (Lepidoptera: Lycaenidae) inhabiting humid grasslands in East-central Europe. Eur. J. Entomol. 105: 871-877. 
Woyciechowski M., Slowik J. \& Muehlenberg M. 2006: Host of the butterfly, Maculinea teleius, among Myrmica ants in northern Mongolia (Lepidoptera: Lycaenidae; Hymenoptera: Formicidae). Sociobiology 48: 493-502.
Wynthoff I., Grutters M. \& van Langevelde F. 2008: Looking for the ants: selection of oviposition sites by two myrmecophilous butterfly species. Animal Biol. 58: 371-388.

Received June 22, 2010; revised and accepted September 17, 2010 